\title{
Privileging the Bromance: A critical appraisal of Romantic and Bromantic
}

\section{Relationships}

In this research, utilising data from 30 semi-structured interviews, we examine how heterosexual undergraduate men compare their experiences of bromances to that of their romantic relationships (romances). We find that the increasingly intimate, emotive and trusting nature of bromances offers young men a new social space for emotional disclosure, outside of traditional heterosexual relationships. Participants state that the lack of boundaries and judgement in a bromance is expressed as emotionally rivalling the benefits of a heterosexual romance. Our participants mostly determined that a bromance offered them elevated emotional stability, enhanced emotional disclosure, social fulfilment, and better conflict resolution, compared to the emotional lives they shared with girlfriends. Thus, this research provides an empirically grounded conceptual framework for understanding men’s view of close homosocial relationships in comparison to their romantic relationship in the $21^{\text {st }}$ century.

Keywords: Bromance, friendship, homosocial, homohysteria, inclusive masculinity 


\section{Introduction}

The concept of $20^{\text {th }}$ Century friendship between both heterosexual (Ibson 2002) and homosexual (Nardi 1999) men is well-examined in the social sciences. While friendship is primarily experienced by individuals as a complex psychological phenomenon (Poplawski 1989), its dimensions, behavioral requisites and prohibitions are nonetheless socially defined and regulated (Van Duijn 2003). However, during much of the $20^{\text {th }}$ Century, investigations of friendship between men has focused on what is missing, by contrast to what exists in women’s friendships; namely, emotional and physical intimacy (Lewis 1978; Pleck 1975).

Recent research (Robinson, Anderson and White 2017) established a framework for defining and characterizing the popular 'bromance' term by analyzing heterosexual undergraduate men's perspectives on the subject. That study showed that young men openly pronounce love for their bromances and engage in highly intimate behaviors, both emotionally and physically, which have until recently been socially prohibited in same-sex male friendships. In this article, we examine whether close male friendships have the capacity to rival the intimacy and affection traditionally reserved for romantic, heterosexual relationships. We know relatively little about how romantic and peer relations are similar or different (Furham and Showmaker 2007), and this research sets out to examine the similarities and differences between bromances and heterosexual romances, with a specific focus on the nature of intimacy and self-disclosure.

\section{The Influence of Homohysteria on Homosociality}

The level of physical and emotional intimacy expressed between heterosexual young men is dependent on a number of socio-historical variables (Lipman-Blumen 1976; Sedgwick 1985). For example, homosocial intimacy flourished before the modern era (Deitcher 2001). Exemplifying this, late $19^{\text {th }}$ and early $20^{\text {th }}$ century men not only posed for photography in 
physically intimate ways, but they wrote endearing letters to one another and even slept in the same beds (Ibson 2002). Tripp (2005) highlights that, for four years, President Abraham Lincoln shared a bed with his intimate male partner, Joshua Speed, and that President George Washington wrote endearing letters to other men.

However, this intimacy that Tripp (2005) describes began to be policed when the awareness of homosexuality grew in the $20^{\text {th }}$ century, particularly in the 1970 s and peaking in the 1980s. In this epoch, straight men began to fear being homosexualized for displaying physical or emotional intimacy. Consequently, this interfered with the development of close male friendships (Morin and Garfinkle 1978). Instead of the $19^{\text {th }}$ century homosociality, late $20^{\text {th }}$ century hypermasculine discourse arose in response to the mass cultural awareness of homosexuality among Western populations. This was facilitated by the spread of the HIV/AIDS virus, which brought such cultural visibility that it solidified the notion that homosexuals existed in great numbers (Halkitis 2000)—something made even more salient by large numbers of gay men dying from AIDS-related illnesses. Accordingly, The General Social Survey and the British Social Attitudes Survey shows that cultural homophobia reached unprecedented heights in the mid-1980s to early 1990s (Loftus 2001; Clements and Field 2014).

Sociological research from this era highlights that men began to emotionally distance themselves from other men (Komarovsky 1974; Pleck 1975). Lewis (1978) wrote that men “...have not known what it means to love and care for a friend without the shadow of some guilt and fear of peer ridicule” (p.108). Jourard (1971), showed that self-disclosure—a vital component of emotional intimacy—was lacking between males. Instead, young men knew that they had a friendship with another male when they engaged in activities together, like playing sports, drinking, fixing things, or gambling (Seiden and Bart 1975). The difference between the early and later stages of the $20^{\text {th }}$ century was growing recognition in the latter 
half that homosexuality exists as a static sexual orientation among a significant portion of the population, and corresponding antipathy toward it. Accordingly, Anderson (2009) theorizes that it was the fear of being thought gay that ended the physical and emotional intimacy that heterosexual men once shared, suggesting, alongside Ibson (2002) and Kellner (1991), that by the 1980s, heterosexual men were severely regulated in their behaviors.

Anderson’s (2009) Inclusive Masculinity Theory, and his concept of homohysteria explains this shift in the physical and emotional dispositions of men before the first half of the twentieth century and the decades of the latter half. McCormack and Anderson (2014) more recently define homohysteria as the fear of being socially perceived as homosexual— something made possible because heterosexuality cannot be definitively proven amongst straight men in a culture that is both aware and fearful of homosexuality. Subsequently, men are culturally compelled to perform certain overtly heterosexual behaviors and avoid engaging in those that would feminize them. Thus, one way of looking at homohysteria is to suggest that whereas homophobia limits the lives of homosexual men, homohysteria limits the lives of heterosexual men, too (Anderson and McCormack 2016).

The fear of male homosexualisation, and its associated femininity, circulated not only within institutions of education (Connell 1989; Mac an Ghaill 1994), but also among other influential institutions, including sport (Anderson 2005; Connell 1995), government (Ahmed 2013; Boyle 2008) and the military (Dunivin 1994). During this time, the requirement for men to refrain from emotional vulnerability had filtered into almost all aspects of men’s personal lives (Field 1999).

Conversely, matters have been vastly different for women. While Worthen (2014) shows that homohysteria also applies to women, they have been less policed by the structures of homophobia. Hence, women have been able to display a far wider range of emotional behaviors than men (Kring and Gordon 1998; Sprecher and Sedikides 1993; Williams 1985). 
For example, unlike men who maintained friendship through shared activities, women have maintained friendships through sharing emotions and disclosing secrets (Caldwell and Peplau 1982). This is not to say that certain hyper-masculine behaviors did not associate women with lesbianism (Griffin 1998; Worthen 2014), but that women were given more leeway for emotional expression than men. This freedom of expression is more closely associated with young women, as research has shown a decline in the closeness between women who are married (Babchuk and Anderson 1989). Indeed, powerful patriarchal forces have sought to limit the closeness of adult female friendships, as they pose a threat to the strength of male alliances and patriarchal rule (Sedgwick 2015). Accordingly, men have historically denied women seats in cultural institutions (such as sport, the military, academia, religion and business) and have relegated them to the domestic sphere where they have not had the opportunity to form large friendship networks and lobby for equal treatment (Kahlenber, Thompson and Wrangham 2008; Flood 2008).

\section{Expressing love in the 1980s}

Writing in the decade of homohysteria, Cancian (1987) said that we have "a feminine conception of love. We identify love with emotional expression and talking about our feelings” (p.69). Accordingly, Anglo-American male youth of this time would refrain from even using the word love (Williams 1985); they were structured into exceptionally narrow masculine identities that rejected emotionality (Kellner 1991). Instead, they aspired to the muscular, heterosexual, hostile and patriotic action heroes that filled Hollywood (Pope et al. 2000). Love and intimacy for men had no place in this era as it projected a feminine (read homosexual) image. Swearing, abuse, readiness to fight (Dunning, Murphy and Williams 2014) and unemotionality (Cancian 1987) were compulsory male characteristics; boys and 
men did not have the liberty to express fear, weakness, uncertainty, or affection for other men (Plummer 1999).

Pleck (1976) similarly finds men of this era to be restricted in their expression, describing in detail the social confines of male intimacy and emotionality. He found that men were expected to exhibit greater control in their emotional behavior than women, being far removed from their feelings. He goes on to say, "at the same time, men appear to become angry or violent more easily than women and are often rewarded for doing so... [having] greater fears about homosexuality than do women” (p.156). Men were to avoid emotional intimacy with other men, finding and expecting legitimate intimacy and companionship only within the confines of heterosexual relationships with women. There was a great impersonality in male friendships, and women's social exemption to be expressive meant that men were dependent on emotional support almost exclusively from women, whilst equally possessing disdain for their emotionality (Fasteau 1975).

In this era, the cultural fear of homosexuality, and consequent emphasis on masculine stoicism, led men to depend entirely on women for the little emotional disclosure they were socially permitted. Komarovsky (1974), for example, discovered that undergraduate men were more likely to use women as a confidant, as opposed to men. This is problematized by the fact that the antipathy towards homosexuality, and love of stoicism, was propagated years before men enter university. Restrictive masculinity found its routes in the lives of even very young boys. Exemplifying this, Pollack (1999) showed that fathers of this era would withhold their love and affection from their children, and before boys even reached their teenage years, they could be subjected to abusive and shaming torments from peers and teachers for performing feminine behaviours such as skipping and poetry readings for not being 'real boys’ (Pollack 1999). The literature consistently documents a cultural zeitgeist of homophobia, hypermasculinity and emotional abstention among men from the 1970s (Olstad 
1975) through to the 1990s (Pollack 1999), leaving a generation of men with a life of nonintimate male-to-male connections (Collins and Sroufe 1999; Connolly et al. 2000; Tognoli 1980).

\section{Inclusive Masculinity Theory}

Contrasting $20^{\text {th }}$ Century literature on adolescent males, in the $21^{\text {st }}$ Century, young men have a greater social entitlement to express themselves through a diverse spectrum of behaviors and emotions that would have previously socially coded them as gay (Anderson 2014). This occurs without judgment from others (McCormack 2012; Weeks 2007). We use Inclusive Masculinity Theory (Anderson 2009; Anderson and McCormack 2016) to explain this shift in young men’s practice of masculinity.

Inclusive Masculinity Theory is based on the social inclusion of those traditionally marginalized by an orthodox form of masculinity. Inclusive Masculinity theorists argue that a substantial shift—a softening — has occurred among male youth, and that this can be observed with prominence in institutions such as education (McCormack 2011), sport (Adams 2011; Magrath, Anderson and Roberts 2015; Murray et al. 2016; White and Robinson 2016) and social media (Morris and Anderson 2015; Scoats 2015). Young men in these forums align themselves away from orthodox tropes of masculinity and are less concerned about whether others perceive them to be gay, straight; masculine, or feminine (White and Hobson 2015). Embracing and performing inclusive behaviors has meant that male youth have little fear of homosexualization for the performance of femininity or homosocial behavior (SavinWilliams 2005). Simply put, the decline of cultural homohysteria has relinquished heterosexual men's burden to police their gendered behaviors.

Building on the growing body of work of decreasing homohysteria and the changing nature of adolescent masculinities in the $21^{\text {st }}$ Century (e.g. McCormack 2012), young men 
today are now able to have highly intimate homosocial relationships alongside casual friends. Like men of the 1980s, they make friends through sports, drinking, and video games, but unlike men of the 1980s, however, they also shop, dine, vacation, and sleep together (Anderson 2014). They also maintain the opportunity to form deep emotional relationships, based on emotional disclosure with one another (Murray and White 2015). Whereas Bank and Hansford (2000) previously found that male friendships struggle due to emotional restraint, masculine hierarchies and homophobia, many scholars now suggest that that the millennial generation has promoted a culture that is much more inclusive and cohesive (Adams 2011; McCormack 2012; Thurnell-Reid 2012). Significantly, recent research has found that both late adolescent men (Robinson, Anderson and White 2017) and men in their 30s (Magrath and Scoats, forthcoming) believe that the pressures of heterosexual marriage and house buying limit their capacity to maintain such close friendships. Indeed, they recognize the temporal context of university life, and that it grants significant social freedoms that will perish as they enter adulthood. Therefore, age in the context of our research, is highly pertinent.

Instead of aspiring to the likes of Rambo, both qualitative and quantitative research shows that adolescent males today much prefer the feminized charms and homosocial tactility of the members of the boy band One Direction, or popular YouTube vloggers (Morris and Anderson 2015), or the intellect, financial success and charity of Bill Gates (JWT 2013). Young men are also increasingly pursuing interests in the arts, music and fashion industries, (Edwards 2006; McCormack 2012), which illustrates the diversification of male norms. What recent generations of men would have considered a highly feminized notion of masculinity, today's adolescents and young men have greatly expanded upon the gendered and sexual behaviors that are not only permissible, but expected of their friends (Adams 2011; McCormack 2012). 
In middle to late adolescence, when many young men are at university, there is an increased opportunity and desire among young men to form peer attachment bonds, whereby deep interdependent relationships are developed premised on self-disclosure and intimacy (Collins and Sroufe 1999). This can occur with either romantic partners or same-sex friends (Kobak et al. 2007). This yearning for intimate bonding arises as young men search for independence from their parents and seek new avenues for advice and companionship (Collins and Repinski 1994). Whilst most of these friendships will not be enduring, some will become highly intimate friendships with a small minority of friends providing a 'safe haven' for full emotional disclosure (Kobak et al. 2007) that is known to them as a bromance.

\section{The Bromance}

Inclusive behaviours have been widely identified in popular television programmes and films, where the majority of scholarly attention on bromances has been focused (Boyle and Susan Berridge 2014). Whist 'buddy movies' have existed since the late 1980s (Fuchs 1993), the relationships between the two leading male characters have become more sentient and compassionate than ever before in mainstream cinema. Gill and Hansen-Miller (2011) describe a new type of film called the 'Lad Flick' or 'Lad Movie,' explaining that these films are a hybrid of the 'buddy movie' and 'romantic comedy’ genre that depict intimate male friendships. Blockbuster films such as 21 Jump Street (2012), Due Date (2010) and The 40Year Old Virgin (2005) have drawn attention to men’s capacity to constitute complex and dynamic relationships grounded in male closeness, trust and homosociality; at least in movies. Indeed, recent research revealed that young men use these types of films as a reference point when defining the bromance and how it operates (Robinson, Anderson and White 2017). As Kusz (2010) highlights, the narratives and relationships played out on screen generally reflect the way we understand our own lives. Thompson (2015) notes that there is disagreement among scholars 
regarding both the benefit of having such a phenomenon as the bromance, and its definition, nonetheless concluding that television and film are "highlighting a subtext of male emotion within bromance[s] that warrants further exploration” (p.3).

The bromance term was popularized among the mainstream media around 2005 when there was a sharp rise in the amount of on screen bromances (Boyle and Susan Berridge 2014; DeAngelis 2014; Gill and Hansen-Miller 2011). Of the minimal academic work conducted around the concept, it is exclusively movie and celebrity culture focussed. The term was adopted in an attempt to account for the increasingly intimate and emotional affection being displayed between heterosexual men on the silver screen and in celebrity culture (DeAngelis 2014). Accordingly, the vast majority of scholarly attention paid to the bromance revolves around media analysis; work that highlights the changing nature of male friendships in movies and television (DeAngelis 2014).

We recently documented how heterosexual men at a UK university engage with the bromance (Robinson, Anderson and White 2017). Through interviewing participants about their involvement in bromances, and how their experiences influenced their understanding of the term, data showed that bromances are achieved through certain social freedoms concerning shared interest, emotional intimacy and non-sexual physical intimacy. Bromances achieved an important level of cultural resonance and meaning to the men, with those involved describing themselves as holding a brotherly or girlfriend type status with their bromance.

Important for the social creation of same-sex intimacy among heterosexual men, the participants also shared a unanimous definition and understanding of what a bromance is. It was expressed to be an intimate same-sex male friendship based on unrivalled trust and selfdisclosure that superseded other friendships. The men publically expressed 'love' for their 
bromance[s], describing intimate examples of emotionality and physical intimacy that they had shared in such friendships.

The decisive component that characterised these friendships was demonstrated through the emphasis placed on a 'lack of boundaries' and seemingly 'nothing being off limits.’ In line with these findings, Hammarén and Johansson (2014) suggest that Bromances are same-sex male relations that "emphasize love, exclusive friendship, and intimacy...[and] are not premised on competition [or hierarchies]” (p.6).

The cultural adoption of the bromance term represents an increased recognition that young men are permitted to have more diverse and homosocial masculine identities. Their behavior shows that, contrasting to the 1970s (Olstad 1975), 1980s (Askew and Ross 1988) and 1990s (Kimmel 1995; 2004; Pollack 1999) research, young heterosexual men are now able to confide in each other, and develop and maintain deep emotional friendships based on intimacy, and the expression of once-taboo emotional sentimentality.

\section{Methods}

\section{Participants}

Over a three-month period, between August 2014 and November 2014, 30 semi-structured, interviews into the romantic and bromantic lives of undergraduate males were conducted. The interviews were conducted by a middle age professor on the university campus, at times to suit the participants. To be part of the research, participants needed to identify as heterosexual and be in the second year of their university studies. The limitation to secondyear students was to enable the examination of men who had sufficient time to develop friendships with their university peers_-having had 18 months to befriend and develop intimate bonds with other men and live in the same house as close male friends.

We recruited all 30 students from various across the university sports department through advertising in lectures and word of mouth, with all of the participants presenting 
themselves to the researchers. We recruited 18 of the students from one particular class for this study because of the ease of access, with the remaining 12 in the same degree program volunteering to be interviewed through snowball sampling. We stopped interviewing at 30 because we had reached data saturation. The same participants were used for Robinson, Anderson and White's (2017) research on conceptualizing the bromance; all having identified that they have been, or are currently, involved in a bromance and a romantic relationship.

To assure that the men we interviewed were not strategically presenting positive or overly-exaggerated support for gay men and male homosexuality (a prerequisite for inclusive masculinities), 18 months prior we distributed Herek’s (1988) Attitudes Towards Gays and Lesbians scale to these students. The survey was administered anonymously upon the students’ first day of arrival at the university. Results showed wide support for male homosexuality which meant that all men espoused pro-gay attitudes on arrival at university.

Although men were not selected for race, the virtually exclusive white student body of this British university limited our analysis. The sample was white, with only one exception. The sample was also populated by participants from middle-class backgrounds. We do not therefore conduct a race or class analysis with this research, limiting our findings to white, middle-class, heterosexual, undergraduate men from one university. We identify the demographic of importance to this research as that of age and gender, and use this sample to develop and discuss the ways young men perceive the value of their bromances compared to that of their romances.

\section{Procedures}

Participants were asked to discuss their experiences of bromances and the homosocial aspects of their same-sex friendships, before being asked how those intimacies compare to those shared with their romantic partners / girlfriends. The line of questioning intended to 
tease out what boundaries (or lack of) bromances and romances operate under. Particular focus was given to limits of self-disclosure and emotional intimacy.

After transcribing the interviews, the participants' narratives were coded for themes relating to their views about bromances, same-sex friendships and romances. Coding was generated from themes documented in research notes after each interview and co-verified with each researcher. For that reason, the process permitted a level of mutual consistency, principally generating more valid data (Denscombe 2002). 20\% of the codes were then subjected to inter-rater reliability with an outside academic not named on this paper.

The ethical procedures of the British Sociological Association have been followed. This includes participants' right to view transcripts, the right to withdraw from the study, making anonymous the participants' names and the name of their university. Participants were provided with an information sheet with the investigators' contact information, aims of the study, consent forms and indication that there was no penalty for not participating. To promote disclosure and confidence in the research process, the participants were reassured intermittently that their data was entirely anonymized.

\section{Results}

Each of the 30 men interviewed for this research described themselves as having at least one bromance and at least one romance, in either the past or present. When describing what he understood a bromance to be, Bruce compared his bromance to a romance, "We are basically like a couple...we get called like husband and wife all the time” and Martin agreed, "It's like having a girlfriend, but then not a girlfriend.” Hamish went as far to say “It’s your best friend. You are closer to him than anyone. They are like a guy girlfriend.” It was clear from the participants that similar behaviors and feelings existed in both bromantic and romantic relationships, which complicates the differentiation of the two. 
As the central theme of enquiry, all participants were directly asked to explain what the difference is between a bromance and romance. Most described this as a difficult question. Chris, articulated what many suggested:

That's a very hard question to answer. I feel like I've got to say that there is a difference. But I really don’t know. I can’t really identify a clear difference. There is a different feeling, but nothing I can particularly describe. Oh! A romance is with a girl and a bromance is with a guy [he laughs].

Participants suggested that the primary difference between a bromance and a romance ultimately hinged on their desire for sex with their romance, and not their bromance. Aaron tried to model how the two were different, suggesting that there are three factors to consider, "sexual, emotional and personality. A bromance needs the last two and a girl needs two including sexual.” Bob just said, “Sex, really. That’s all.” Aaron said, “When you have a bromance with a friend, it's motivated by your interest in that person, love and friendship, and not because you want sex.” Indeed, sexual desire is often perceived as the traditional missing link between a friendship and a romantic relationship (Thompson 2006). Beyond the need for sex, we found that for this cohort of men, bromances performed a very similar, and often superior function to romances.

\section{Disclosure, Emotionality and Physical Intimacy}

The vast majority of participants suggested that they have a preference for disclosing personal matters and exclusive secrets sharing with their bromance[s], more so than their romances. They were clear that a bromance offers a deep sense of unburdened disclosure and emotionality based on trust and love, in which vulnerabilities can be revealed. Of the men interviewed, 28 out of the 30 said that they would prefer to discuss personal matters with a 
bromance than a romance. They felt able to express and emote in their bromances, and divulge their most personal issues, without ridicule.

Brad said, “There are absolutely things I tell my bromances and not the girlfriend. She expects so much from the relationship and will have a go if I say something out of line, and with Matt we just tell each other everything.” Harvey shared a similar sentiment, “There are no boundaries between us [he and his bromance] and what we can say. I couldn't tell her [girlfriend] as much as him cause she might not like me after.” When asked to elaborate, Harvey explained, “Well, for example, Tim knows I love listening to Taylor Swift and Beyonce, but I keep that quiet because she would judge me. I feel like I have to be more manly around her.”

Bob used a health related example to clarify his favorability of disclosing to a bromance. "If I found a lump on my testical, I’d talk to [bromance] rather than my girlfriend.” The notion of a health concern was named by five other men as well. Hamish spoke about when he was in hospital. "Charlie was there for me all the time when I was recovering. But, when my girlfriend came, I kind of wanted her to leave so that I could have a laugh with Charlie instead of being all serious like she is.” George gave a different kind of example. He spoke of his desire to for his girlfriend to finger him (penetrate his anus during sex). However, he thought his girlfriend would think he was gay, and thus ruining the relationship, he had only told his bromance about his sexual desires.

Martin said, "because you can be more truthful about stuff, and because he wont judge me, it’s easier to talk to him and I don't have to hold back.” Robbie spoke in more general terms, “They [romances] can’t do the laddish banter we do. You can piss around and go dirty in your conversations with bro's, but you don’t tell girlfriends about that stuff. With guys I know where I stand.” Hamish similarly said that, “Bromances are more honest and have more banter cause you say things to the guys you wouldn't' want to say to the girl.” 
Beck believed that this increased disclosure to other men is because, “A girlfriend will judge you and a bromance will never judge you.”

Ollie gave an example of where he didn’t want his girlfriend to see him emote. "When I was upset about my granddad, I wouldn’t let the girlfriend over cause I didn’t want her to see me upset. Stewart kept me company, and I think it pissed her off.” He elaborated, “Stewart stayed in my bed till the morning." It is this type of behavior that led the men in this study to widely proclaim love for their bromance(s). Ollie was not the only man to be physically intimate with his bromance.

Of the 30 men interviewed, 29 said that they had experienced cuddling with a same sex friend, and many expressed that it occurred frequently with their bromances. Aaron said that with his bromance, "We hug when we meet, and we sleep in the same bed when we have sleepovers. Everyone knows it, and nobody is bothered by it because they do it as well.” Alan shows that there is no shame in this behavior, “There's a great photo of me and Tom on Facebook cuddling” he said. Patrick said, “I think most guys in bromances cuddle, it’s a usual in my main friendship group. It’s not a sexual thing, either. It shows you care.”

Consistent with other research on British undergraduate men (Anderson, Adams and Rivers 2012), kissing was also widely spoken about as a sign of affection for a bromance. Robbie said, "You see guys kissing and cuddling each other loads. It’s never an issue to anyone.” Tony said, "I kiss him [bromance] all the time” and Max said that in his bromance, "I hug him and kiss him and tell him I love him.” Beck said, “Guys nowadays, in my generation, there is so much kissing between guys because it’s showing affection.”

Significantly, for men with girlfriends, their bromantic cuddling is known by their girlfriend's and, ostensibly, approved. Joe said, for example, that his girlfriend knows that he has a strong bromance, and that he cuddles with him. When asked if his girlfriend is 'okay with that,' he replied, “My girlfriend is fine with it.” Similarly, Tony told us that he has a 
"fair few bromances” and has also been in a relationship with his girlfriend for seven years. Yet he is still, "quite comfortable touching other people [males]" and that his girlfriend is “not bothered by it.” So whereas one might think that heterosexual men with girlfriends might not desire or seek same-sex intimacy, this is not the case. The physical interactions that these men engage in with other men are unanimously expressed to be devoid of sexual desire. However, it remains that they desire to be physically intimate, albeit non-sexually, with their bromances; a behavior traditionally reserved exclusively for romantic relationships.

\section{Hiding from Judgement}

There was a clear acknowledgement among the participants that bromances had a heightened capacity for emotional disclosure, beyond that which they felt free to express to romances. Many participants suggested that they limit their emotionality and disclosure to their girlfriends because they feel compelled to self-monitor, perform and 'act differently' to regulate their girlfriend's perception of them. They explained that there was more judgment passed between romances (back and forth) than bromances, and more emotional instability, meaning that it was sometimes easier to refrain from certain disclosures for the sake of conflict limitation and/or receiving negative judgement. Conversely, bromances were expressed to be rather boundless, in terms what can be said without judgement.

Specifically, participants said that they did not want to get in trouble for saying or doing the 'wrong thing.' As Harvey explained, “You want to project a better self [to your romance] and maintain the standard you had at the beginning of the relationship.” Beck explained the other side to this, "With a guy, you don't' have to impress them. You are just so relaxed around each other. Sometimes it feels like I'm always on eggshells with her [girlfriend].” 
The fear of persecution for displaying desires for other women in front of their romances was also described as problematic for these men. Many would not talk about, or even look at other girls in front of their romances. This is because they believed that they would cause relationship trouble for doing so. Hamish said, "You defiantly have to be more careful. My god, if you talk about another girl, you get your head ripped off” and David agreed. “The first rule is you don’t speak about other girls! It just causes trouble.” Toby said: I feel comfortable talking to my girlfriend about most things. Although, if I look at girls, or mention other girls, she’s always suspicious of me. I've said stuff in front of her before and I got in trouble. So, now I know to keep quiet. The guys say I'm under the thumb and they're probably right.

Accordingly, the desire to project a "better self" to romances has caused these men to modify their behavior through attempting to uphold what they consider to be a false image of themselves. Harvey said, “The words I'd use with a friend are different. I found myself talking in a correct manner to my girlfriend.” Liam said that with his bromances, he is free to "say more things that won't result in an argument." George adds to this, suggesting, "with a girl you kind of have to think a lot more before you say things, because of the way they will react.” Max gave an example, “I don’t feel like I can say no to anything she asks. If she wants me to come over and I'm too tired, or busy, I still drop everything and go to avoid arguing.” Mark said:

I don't talk to my girlfriend about the drugs I use, even weed, cause she will definitely have a go... I lie about things to keep her happy, and I nod along with all her plans for our future. I only speak to [bromance] and [bromance] about the fact I want to travel for a year and maybe even move abroad.”

One participant felt that he needed to artificially maintain a masculine identity; Jay said, "I have to try and keep up this figure of masculinity [around his romance], whereas a 
guy friend isn’t going to care.” Under the homosysteric culture of the 1980s and 1990s, men would find themselves strictly monitoring their behavior around other men, however, within this cohort, this self-checking amongst male friends has diminished.

On the other hand, bromances were described to be more fluid and relaxed. Regi said, "If I dont talk to [bromance] for a while, they are cool. But girls would freak out...In my bromance nothing is off limits.” David agreed, "I hold nothing back in my bromance. There are no boundaries like there is with my girlfriend.” Jason added, "With the guy... you are always on the same wavelength. I don't think girls can relate to me in the same way guys can.” Adam said, "With my last girlfriend I would always have to prioritize her over my friends, or it would always end up with me getting an ear full; or no sex [he laughs]. Zani (1993) finds that conflicts in romances are often caused because of jealousy over the amount of time one spends with their same-sex friends, although, this does not surmount to the jealousy one is likely to feel if a partner is spending time with someone from the opposite sex (Roth and Parker 2001).

Adam highlights a point made by several others; that sex (or a lack of) can be used as a pawn to reward boyfriends for being loyal and appreciative of their girlfriends; often at the expense of male bonding. Nathan said, "I know if I choose to go out with the guys instead of her, she won't have sex with me for like a week.” When speaking about the difference between a bromance and a romance, Henry said, “The only thing with a girl is that it brings sex into it - if you are nice to them for the whole day that is.” Other men similarly suggested that to achieve sex with a romance, it often came at a cost. Regi said, “They [girlfriends] always feel like they should take priority, they expect so much from the relationship, and we give them priority because of sex. It’s because we can’t control our sex drive.”

Other participants could relate to this, recognizing that it was problematic: that their desire for sex was not a good thing for the emotional side of their romantic emotional 
relationship. Some felt that the emotional intimacy they shared with women was artificially enhanced in order to achieve sex and maintain the romance. Harvey said, "In romances, people don't like to truly show their feelings. Other than that, the only difference between romances and bromances is the sexual desire." Sam said, "With women, the sexual stuff is great, but the romantic stuff might not be as honest because you will say whatever for sex.” Joe went as far to call this sexual pollution, explaining, "Sex is expected and it interferes with the emotional stuff...bromances are stronger because there is no sexual pollution.” Beck agreed, "Being able to be truthful with a bromance can be superior to a romance, but you don't get the sexual pleasure.” For these men, sex clearly holds power in a heterosexual relationship, leading many to suggest that it can complicate the emotional side of the relationship.

\section{Conflict Resolution}

Arguments and conflict resolution were discussed concerning both bromances and romances. When questioned, the participants overwhelmingly stated that arguments with girlfriends were more intense, trivial and long lasting in comparison to their bromances. When speaking about arguments with his girlfriend, Harvey said, "She will store up something you did wrong two years ago and recall it, with the exact date and time.”

This example was given in similar terms by other participants, too. Toby agreed, “With men, its over. But women are very good at remembering things.” Adam said, "I’d say guys are a less emotional about arguments. So if you say something offensive, they wouldn't take it as strong as a female.” Hamish said that this makes personal conflict easier to overcome with a bromance. He explained that if he has a problem with a bromance, he handles it by saying, “Stop being a prick.” He adds: 
You can’t say that to a girlfriend. It will cause all sorts of trouble...Sometimes we

[bromance] clash and quite often he says 'ah fair enough, I shouldn’t have done that.'

Then that's it. It's over. We just move on.

Hamish suggested that men overcome conflict easier because, "We are more honest with each other and perhaps more forgiving.” Adam said, "Women have culturally been taught to take things more literally and get upset, whereas guys can laugh out their frustrations. So it’s easier with guys.” Gavin said, “There isn’t anything that can go wrong in a bromance. Unless you're specifically a massive tool.” Theo argued with his bromance recently, however it resolved quickly. "We can't hold an argument. We just let it go, We talk about it,” he said. Liam summarized a variety of these findings in saying:

There are just things that you can tell guys that you can't tell a girlfriend: things that if you told to a girlfriend it would start an argument. So you don't tell her. You tell him [the bromance], instead. This allows you to talk about it, to get it out and process it; and it keeps the peace with the girlfriend.

It is for these reasons that this research unmasks perhaps uncomfortable and socially frowned-upon ideas about heterosexual relationships. It questions the quality of relationships for young straight men and women and advocates that, perhaps, heterosexual men widely benefit from long term intimate (albeit not sexual) relationships with other men. When asked if a long term heterosexual same-sex relationship was possible, Adam offered, "Yeah, it seems like a logical idea in fact.” Harvey felt these relationships would have more success, concluding, "Lovers are temporary, a bromance can last a lifetime.”

\section{Discussion}

By engaging with a critical appraisal of bromances, alongside traditional heterosexual romances, we illustrate how these 30 millennial men conceptualize and express the value of 
their close male friendships. The most significant finding in this study concerns the virtually unanimous narrative that these men found it easier to open up and express their feelings to their bromances, more so than their romances. This was suggested for two reasons. First, the most consistent finding concerned the lack of emotional boundaries and limits in bromances. Bromances were described — even if overly idealized — as being judgement free, and having a lack of boundaries which allows them to push to margins of traditional masculinity through more physical and emotional behaviors. Conversely, many of the men did identify boundaries in their romances. Often, they could not talk fully about their; interests, anxieties, health and sexual desires; even when emerging adults often idealize romantic partners and exaggerate their supportiveness (Murray, Holmes, and Griffin 1996).

Second, men we interviewed expressed that, with a romance, one was constantly posturing and self-monitoring, not only to achieve desired heterosexual sex, but to prevent relationship destruction. The men would restrict what they would say, and instead act the part of the adoring boyfriend. The men reasoned that they did this because, in their view, women held onto grudges longer than men and were more unpredictable in their emotional responses, often recalling and reusing historical instances of conflict in later arguments. Indeed, some scholars reason that gendered stereotypes about emotionality inherently affect our display of emotion (Shields 1991), with women continuing to report, from a self-gauge perspective, that they have more frequent and intense emotional experiences and are more sensitive to their feelings (Sprecher and Sedikides, 1993; Kring and Gordon 1998). On the contrary, the participants found it much easier to resolve disputes and arguments with their bromances because they found them to be more forgiving. Consequently, they were less guarded in their personal disclosure and identity management with their bromances, despite their romances following a more traditional trajectory. 
Many felt that the sexual dimension of a heterosexual relationship was implicitly linked to, and interfered with, having an efficacious and emotionally stable relationship. Baumeister and Twenge (2002) explain the dissonance highlighted by the men’s comments regarding the exchange of adoration for sex in a heterosexual relationships. They reason that under the Female Control Theory, women are able to regulate men's behaviour and increase their affection for women through restricting access to sex. Consequently, men may engage in intense and prolonged instances of female adoration, or "being nice” as one participant put it. The participant's preoccupation and essentialist approach to sex does not recognize the male capacity to withhold sex from their romantic partners to gain affection however. Unlike romantic relationships, bromances operate as "non-profitable" friendships that are based on mutual compatibility (Hammarén and Johansson 2014); not on the pursuit of selfgratification. For the men in this study, the absence of sexual desire in a bromance has placated the prospect of conflict.

There was a conclusive determination from the men we interviewed. On balance, they argued that bromantic relationships were more satisfying in their emotional intimacy, compared to their heterosexual romances. They saw social liberty in a bromance that exceeds the disclosure and openness achievable in their romantic relationships. This was articulated to be because of the effort required to maintain a romance, compared to the ease upon which two males can relate in a bromance. This is perhaps why men without girlfriends did not seem altogether longing for one.

We contend that the male preference for emotionality between other men, rather than women, has come about due to a significant cultural shift in the structure of masculinity. In the time that has passed since the 1980s, where a cultural zeitgeist of hegemonic masculinity existed, young men have rapidly come to esteem a more advanced and complex level of emotionality in their same-sex friendships. Men would have previously denounced the 
presence of intimacy in their friendships (Walker 1994), but they now embrace and speak of it openly. Where men had once reserved secret sharing and exclusive disclosure for women only (Davis and Todd 1982; Fasteau 1975; Komarovsky 1974), it was clear from our research that these millennial men have now transcended the emotional regulation experienced in the homohysteric era before them, to become highly tactile, inclusive and caring towards other men.

There are however significant and worrying results here for women. These men perceived women to be the primary regulators of their behavior, and this caused distain for them as a whole in some instances. The men often generalized personal experiences to women as a collective, under an 'us and them' binary which associated all women with any negative experiences the men had. The narratives used by the participants undoubtedly reflect the allegiances that they feel towards their own sex, and the nature of their disclosures suggests that some have a limited respect for their past and present girlfriends. Much in the same way that woman are portrayed in contemporary cinema as objects for male gratification (Gill and Hansen-Miller 2011), several of the participants spoke of women they knew in a generally negative way. There was a tendency, as in Hollywod, to deliver sexist perspectives in a humorous and banterous way to deter accusations of sexism, and this is problematic. Mehta and Strough (2009) propose that the strengthening of homosocial bonds contributes towards the devaluing of cross-sex socialization, and it may be that the rise of the bormances may not altogether be liberating and socially positive for women. We believe that the binary approach to questioning (i.e bromancs vs romances), and the fact that the interviewer was of the same sex as participants, may have subtly influenced the nature of the language used to describe women.

Men in this research highlight that the physical and emotional dimensions of bromances resemble the traditional expectations of romantic companionship: namely, the 
declarations of love, kissing, cuddling and exclusive emotional confidence. We show, that whilst one of the fundamental differences between bromances and romantic relationships is sex, these are less rigid due to the progressively inclusive attitudes around same-sex touch. We find that the organization of bromances and romantic relationships are not dissimilar from one another. Under the rubric of inclusive masculinity, young men at this university are embracing their innate desire to search for companionship (Collins and Repinski 1994; Zorn and Gregory 2005), particularly with men, free from social stigma.

These findings are consistent with Anderson's notion of inclusive masculinity (2009), and resonate with other recent findings on young men (Furman and Shomaker 2008; Hammarén and Johansson 2014; Zorn and Gregory 2005). It seems that, for the millennial men in this and other studies, they do not hold back on embracing their capacity for emotional versatility; rather, they are free to develop dynamic relationships with other men, offering them "valuable, tangible and socio-emotional support” (Zorn and Gregory 2005. p.211).

There are interesting potential implications for domesticity, too. These heterosexual millennial men cherish their close male friends; so much so that they may even provide a challenge to the orthodoxy of traditional heterosexual relationships. Given that young men are now experiencing a delayed onset of adulthood, and an extended period of adolescence (Arnett 2004), men may choose to cohabit as a functional relationship in the modern era. Just as many of the men in this research share exclusive same-sex houses while at university, they may continue with their bromances and domesticity well beyond university years. Howard (2012) has already found some older men doing this, and Magrath and Scoats (forthcoming) finds that men in their 30s have regrets about not maintaining their bromances into later life, with marriage being a key barrier to this. This, again, is another indication that bromances may not altogether benefit cross-sex relations. In other words, because heterosexual sex is 
now achievable without the need for romantic commitment (Bogle 2008), and because bromances are privileged for these men, the bromance could increasingly become recognized a as genuine lifestyle relationship; whereby two heterosexual men can live together and experience all the benefits of a traditional heterosexual relationship.

\section{References}

Adams, Adi. "“Josh wears pink cleats”: Inclusive masculinity on the soccer field." Journal of homosexuality 58, no. 5 (2011): 579-596.

Ahmed, Sara. 2013. The cultural politics of emotion. New York: Routledge

Anderson, Eric. 2005. In the game: Gay athletes and the cult of masculinity. New York: University of New York Press.

Anderson, Eric. 2009. Inclusive masculinity: The changing nature of masculinities. New York: Routledge

Anderson, Eric. 2014. 21st Century Jocks: Sporting Men and Contemporary Heterosexuality. New York: Macmillan.

Anderson, Eric, Mark McCormack, and Harry Lee. "Male team sport hazing initiations in a culture of decreasing homohysteria." Journal of Adolescent Research 27, no. 4 (2012): 427-448.

Anderson, Eric. and Mark McCormack. Cuddling and spooning: Heteromasculinity and homosocial tactility among student-athletes. Men and Masculinities, 18, no. 2 (2015):214-230.

Anderson, Eric, and Mark McCormack. "Inclusive Masculinity Theory: overview, reflection and refinement." Journal of Gender Studies (2016): 1-15, DOI:

10.1080/09589236.2016.1245605

Anderson, Eric, Adi Adams, and Ian Rivers. "“I kiss them because I love them”: The emergence of heterosexual men kissing in British institutes of education." Archives of sexual behavior 41, no. 2 (2012): 421-430. 
Arnett, Jeffrey Jensen. 2004. A longer road to adulthood. New York: Oxford University Press

Askew, Sue, and Carol Ross. 1988. Boys don't cry: Boys and sexism in education. Milton Keynes: Open University Press.

Babchuk, Nicholas, and Trudy Anderson. Older widows and married women: Their intimates and confidants. International Journal of Aging and Human Development, 28 (1989): 21-35.

Baker, Phyllis L., and Douglas R. Hotek. "Grappling with gender: Exploring masculinity and gender in the bodies, performances, and emotions of scholastic wrestlers." Journal of Feminist Scholarship 1 (2011): 1-15.

Bank, Barbara J., and Suzanne L. Hansford. "Gender and friendship: Why are men's best same-sex friendships less intimate and supportive?" Personal Relationships 7 no. 1 (2000): 63-78.

Bogle, Kathleen A. 2008. Hooking up: Sex, dating, and relationships on campus. New York: New York University Press.

Boyle, Ellexis. 2008. "Building a body for governance: embodying power in the shifting media images of Arnold Schwarzenegger." PhD diss., University of British Columbia.

Boyle, Karen, and Susan Berridge. "I Love You, Man: Gendered Narratives of Friendship in Contemporary Hollywood Comedies." Feminist Media Studies ahead-of-print (2012): $1-16$.

Caldwell, Mayta A., and Letitia Anne Peplau. "Sex differences in same-sex friendship." Sex Roles 8 no. 7 (1982): 721-732.

Cancian, Francesca. 1989. "Love and the rise of capitalism." In Risman, B and Schwartz, P (Eds.), Gender in intimate relationships. Belmont: Wadsworth. Pp. 12-25. 
Channon, Alex, and Christopher R. Matthews. "'It is what it is’: Masculinity, homosexuality, and inclusive discourse in mixed martial arts." Journal of Homosexuality. (2015) Just accepted.

Chen, Elizabath J. "Caught in a bad bromance." Texas Journal of Women and Law 21, no. 2 (2011): 241-267

Clements, Ben, and Clive D. Field. "Public opinion toward homosexuality and gay rights in Great Britain." Public Opinion Quarterly 78, no. 2 (2014): 523-547.

Collins, W. Andrew, and Daniel J. Repinski. "Relationships during adolescence: Continuity and change in interpersonal perspective." (1994). In R. Montemayor, G. R. Adams, and T. P. Gullotta (Eds.), Personal relationships during adolescence. Thousand Oaks, Sage. Pp. 7-36.

Collins, W. Andrew, and L. Alan Sroufe. "Capacity for intimate relationships." (1999). In Furman, WB. Bradford Brown and Candice Feiring (Eds.), The development of romantic relationships in adolescence pp. 125-147.

Connell, Robert W. 1995. Masculinities. Berkeley: University of California Press.

Connell, Robert W. "Cool guys, swots and wimps: the interplay of masculinity and education." Oxford review of education 15, no.3 (1989): 291-203.

Deitcher, David. 2001. Dear friends: American photographs of men together, 1840-1918. Michigan: Harry N Abrams Inc.

Dermott, Esther. 2008. Intimate fatherhood: A sociological analysis. New York: Routledge. DeAngelis, Michael. 2014. Reading the Bromance: Homosocial Relationships in Film and Television. Wayne State University Press: Detroit.

Denscombe, Martyn. 2002. Ground rules for good research. Leicester: Open University Press. 
Dunivin, Karen O. "Military culture: Change and continuity." Armed Forces \& Society 20, no. 4 (1994): 531-547.

Dunning, Eric, Patrick J. Murphy, and John Williams. The Roots of Football Hooliganism (RLE Sports Studies): An Historical and Sociological Study. New York: Routledge, 2014

Field, Tiffany. “American Adolescents Touch Each Other Less and are More Aggressive Toward Their Peers as Compared With French Adolescents.”. Adolescence 34, no. 136 (1999): 753- 758.

Flood, Michael. "Men, Sex, and Homosociality How Bonds between Men Shape Their Sexual Relations with Women." Men and masculinities 10, no. 3 (2008): 339-359.

Fuchs, Cynthia. The buddy politic. Screening the male: Exploring masculinities in Hollywood cinema, (1993). In I Rae and S Cohan (eds), Screening the Male: Exploring Masculinities in Hollywood Cinema. New York: Routledge, pp.194-210.

Griffin, Pat. Strong women, deep closets: lesbians and homophobia in sport. Illinois, Human Kinetics, 1998.

Hagestad, Gunhild O., and Vaughn RA Call. "Pathways to Childlessness A Life Course Perspective." Journal of Family Issues 28, no. 10 (2007): 1338-1361.

Halkitis, Perry N. "Masculinity in the Age of AIDS: HIV-Seropositive Gay Men and the" Buff Agenda". Research on men and masculinities series 12 (2007): 130-151.

Hammarén, Nils, and Thomas Johansson. "Homosociality In Between Power and Intimacy." SAGE Open 4, no. 1 (2004): 1 - 11

Gill, Rosalind and Hansen-Miller, David."Lad flicks: discursive reconstructions of masculinity in popular film." (2011). In H Radner and E Pullar (eds), Feminism at the movies: understanding gender in contemporary popular cinema. New York: Routledge, pp. 36-50. 
Hammarén, Nils, and Thomas Johansson. "Homosociality." SAGE Open 4, no. 1 (2014): 2158244013518057.

Herek, Gregory M. "Heterosexuals' attitudes toward lesbians and gay men: Correlates and gender differences." Journal of Sex Research 25, no. 4 (1988): 451-477.

Howard, Hillary. A Confederacy of Bachelors. New York Times Aug 3, 2012.

Ibson, John. Picturing Men: A Century of Male Relationships in Everyday American Photography. Illinois: University of Chicago Press, 2002.

Jeffords, Susan. The remasculinization of America: Gender and the Vietnam war. Vol. 10. Bloomington: Indiana University Press, 1989.

Jourard, S. 1971. The Transparent Self. D. Van Nostrand.

JWT. www.slideshare.net/jwtintelligence/ the- state- of- men, 2013.

Kellner, Douglas."Film, politics, and ideology: Reflections on Hollywood film in the age of Reagan." Velvet Light Trap 27 (1991): 9-24

Kimmel, Michael. Manhood in America. New York: Free Press, 1995.

Kimmel, Michael S. "Masculinity as homophobia: Fear, shame, and silence in the construction of gender identity." Race, class, and gender in the United States: An integrated study (2004): 81-93.

Kobak, Roger, Natalie L. Rosenthal, Kristyn Zajac, and Stephanie D. Madsen. "Adolescent attachment hierarchies and the search for an adult pair-bond." New Directions for Child and Adolescent Development 117 (2007): 57-72.

Komarovsky, Mirra. "Patterns of self-disclosure of male undergraduates." Journal of Marriage and the Family 36, no. 4 (1974): 677-686.

Kozloski, Michael J. "Homosexual moral acceptance and social tolerance: are the effects of education changing?" Journal of homosexuality 57, no. 10 (2010): 1370-1383. 
Kring, Ann M., and Albert H. Gordon. "Sex differences in emotion: expression, experience, and physiology." Journal of personality and social psychology 74, no. 3 (1998): 686703.

Lewis, Robert A. “Emotional Intimacy Among Men.” Journal of Social Research 34, no. 1 (1978): 108- 121.

Lipman-Blumen, Jean. "Toward a homosocial theory of sex roles: An explanation of the sex segregation of social institutions." Signs 1, no. 3 (1976): 15-31.

Loftus, Jeni. "America's liberalization in attitudes toward homosexuality, 1973 to 1998." American Sociological Review 66, no. 5 (2001): 762-782.

Luttrell, Wendy. 2012. "Making Boys' Careworlds Visible." Thymos: Journal of Boyhood Studies 6(2): 186-202.

Mac an Ghaill, Mairtin. Making of men. Philadelphia: Open University Press, 1994.

Magrath, Rory, Eric Anderson, and Steven Roberts. "On the door-step of equality: Attitudes toward gay athletes among academy-level footballers." International Review for the Sociology of Sport 50, no. 7 (2015): 804-821.

Magrath, Rory, and Ryan Scoats (Forthcoming). Young men's friendships: Inclusive masculinities in a post-university setting. Journal of Gender Studies.

McCormack, Mark. "Hierarchy without hegemony: Locating boys in an inclusive school setting." Sociological Perspectives 54, no. 1 (2011): 83-101.

McCormack, Mark. The declining significance of homophobia: How teenage boys are redefining masculinity and heterosexuality. New York: Oxford University Press, 2012.

McCormack, Mark, and Eric Anderson. "The Influence of Declining Homophobia on Men’s Gender in the United States: An Argument for the Study of Homohysteria.". Sex Roles 71, no. 3-4 (2014): 109-120. 
Morin, Stephen F., and Ellen M. Garfinkle. "Male homophobia." Journal of Social Issues 34, no. 1 (1978): 29-47.

Morris, Max, and Eric Anderson. "‘Charlie Is So Cool Like’: Authenticity, Popularity and Inclusive Masculinity on YouTube." Sociology (2015), 0038038514562852.

Murray, Ashnil, and Adam White. "Twelve not so angry men: Inclusive masculinities in Australian contact sports." International Review for the Sociology of Sport (2015): 1012690215609786.

Murray, Ashnil, Adam White, Ryan Scoats, and Eric Anderson. "Constructing masculinities in the National Rugby League's footy show." Sociological Research Online 21, no. 3 (2016): 11.

Nardi, Peter M. Gay men's friendships: Invincible communities. Illinois: University of Chicago Press, 1999.

Office for National Statistics. 2012. http://www.ons.gov.uk/ons/dcp171778_366530.pdf

Olstad, Keith. "Brave new men: A basis for discussion." Sex." male/gender. masculine. New York: Alfred, 1975.

Peterson, Grant Tyler, and Eric Anderson. "The performance of softer masculinities on the university dance floor." The Journal of Men's Studies 20, no. 1 (2012): 3-15.

Pleck, Joseph. “Issues for the Men’s Movement: Summer, 1975” Changing Men: A Newsletter for Men Against Sexism 1- 23, 1975.

Plummer, David. One of the boys: Masculinity, homophobia, and modern manhood. New York: Routledge, 1999.

Pollack, William. Real Boys: Rescuing Our Sons from the Myths of Boyhood. New York: Macmillan, 1999. 
Poplawski, Paul E. 1989. "Psychological and qualitative dimensions of friendship among men: an examination of intimacy, sex-role, loneliness, control and the friendship experience." PhD diss., Temple University.

Robinson, Stefan., Anderson, Eric, and Adam White. The Bromance: Undergraduate Male Friendships and the Expansion of Contemporary Homosocial Boundaries. Sex Roles (2017). doi:10.1007/s11199-017-0768-5

Savin-Williams, Ritch C. The new gay teenager. Harvard University Press, 2005.

Scoats, Ryan. "Inclusive masculinity and Facebook photographs among early emerging adults at a British University." Journal of Adolescent Research (2015): 0743558415607059.

Sedgwick, Eve. 1985. Between men: English literature and male homosocial desire. New York: Columbia University Press, 1985.

Sedgwick, Eve. Between men: English literature and male homosocial desire. Columbia University Press, 2015.

Seiden, Anne, and Pauline Bart. 1975. "Woman to woman: Is sisterhood powerful." N. Glazer-Malbin (Ed.), Old family/New family. New York: D. Van Nostrand. (1975): 189-228.

Sprecher, Susan, and Constantine Sedikides. "Gender differences in perceptions of emotionality: The case of close heterosexual relationships." Sex Roles 28, no. 9-10. (1993): 511-530.

Thompson, Lauren Jade. "Reading the bromance: homosocial relationships in film and television." Journal of Gender Studies (2015) ahead-of-print: 1-3.

Tognoli, Jerome. "Male friendship and intimacy across the life span." Family Relations (1980): 273-279. 
Tripp, Clarence Arthur. The intimate world of Abraham Lincoln. New York: Free Press, 2005.

Thurnell-Read, Thomas. "What Happens on Tour: The Premarital Stag Tour, Homosocial Bonding, and Male Friendship." Men and Masculinities 15, no.3 (2012): 249-270. Van Duijn, Marijtje AJ, Evelien PH Zeggelink, Mark Huisman, Frans N. Stokman, and Frans W. Wasseur. "Evolution of sociology freshmen into a friendship network." Journal of Mathematical Sociology 27, no. 2-3 (2003): 153-191.

Walker, Karen. "Men, women, and friendship: What they say, what they do." Gender \& Society 8, no. 2 (1994): 246-265.

Weeks, Jeffrey. The world we have won: The remaking of erotic and intimate life. New York: Routledge, 2007.

White, Adam, and Michael Hobson. "Teachers' stories: physical education teachers' constructions and experiences of masculinity within secondary school physical education." Sport, Education and Society (2015): 1-14.

White, Adam, and Stefan Robinson. "Boys, Inclusive Masculinities and Injury: Some Research Perspectives." Boyhood Studies 9, no. 2 (2016): 73-91.

Williams, Dorie Giles. "Gender, masculinity-femininity, and emotional intimacy in same-sex friendship." Sex Roles 12, no. 5-6 (1985): 587-600.

Worthen, Meredith GF."The cultural significance of homophobia on heterosexual women’s gendered experiences in the United States: A commentary." Sex Roles 71, no. 3-4 (2014): 141-151.

Zani, Bruna. "Dating and interpersonal relationships in adolescence." Adolescence and its social worlds (1993): 95-119. 
Zorn, Theodore E., and Kimberly Weller Gregory. "Learning the ropes together: Assimilation and friendship development among first-year male medical students." Health Communication 17, no. 3 (2005): 211-231 